\title{
Knowledge, attitude and practices regarding cervical cancer and screening among women visiting primary health care in Qatar
}

\author{
F.M. Al-Meer, ${ }^{1}$ M.T. Aseel, ${ }^{1}$ J. Al-Khalaf, M.G. Al-Kuwari' ${ }^{2}$ and M.F.S. Ismail ${ }^{3}$
}

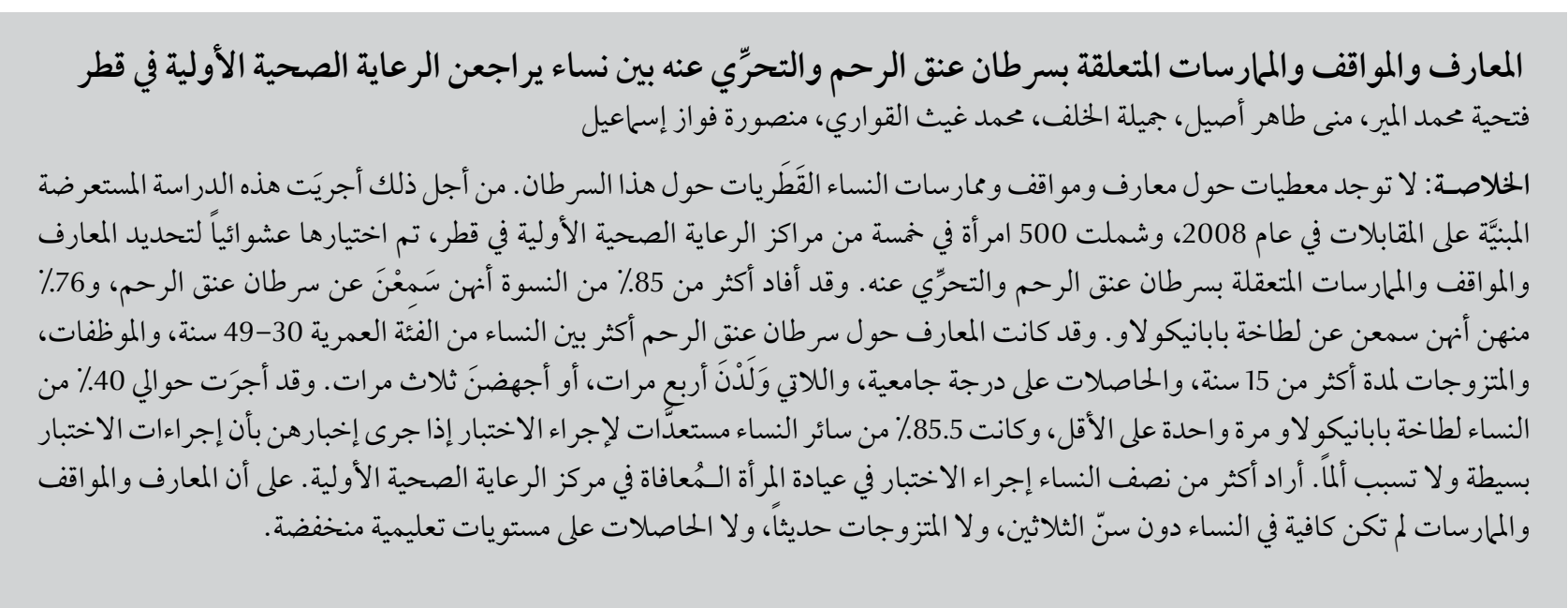

ABSTRACT There are no data on the knowledge, attitude and practices of Qatari women about this cancer. Therefore this cross-sectional interview-based study was conducted in 2008 among 500 women at 5 randomly selected primary health care centres in Qatar to determine their knowledge, attitude and practices regarding cervical cancer and screening. Just over $85 \%$ had heard of cervical cancer and $76 \%$ had heard about the Pap smear. Knowledge of cervical cancer was significantly greater among women aged 30-49 years, and those employed, married for $>15$ years, with a university degree, or who had had 4 births or 3 miscarriages. Almost $40 \%$ had had a Pap smear test at least once and $85.5 \%$ of the rest would have a test if they were told that the procedure was painless and simple. Over half wanted the test to be done in the well-woman clinic at the primary health care centre. Knowledge and practice was inadequate among those under 30 years old, those recently married and those with a lower education level.

Connaissances, attitude et pratiques des femmes consultant un centre de soins de santé primaires au Qatar en matière de cancer du col de l'utérus et de dépistage

RÉSUMÉ II n'existe pas de données sur les connaissances, l'attitude et les pratiques des femmes qatariennes concernant ce cancer. Par conséquent, la présente étude transversale reposant sur des entretiens a été réalisée en 2008 auprès de 500 femmes dans cinq centres de soins de santé primaires sélectionnés aléatoirement au Qatar, pour déterminer leurs connaissances, attitude et pratiques en matière de cancer du col de l'utérus et de dépistage. Un peu plus de $85 \%$ d'entre elles avaient entendu parler du cancer du col et $76 \%$ du test de Papanicolaou. Les connaissances sur ce cancer étaient nettement supérieures chez les femmes âgées de 30 à 49 ans, ayant une activité professionnelle, mariées depuis plus de quinze ans, diplômées de l'université, ou qui avaient eu quatre accouchements ou trois fausses couches. Près de 40 \% avaient effectué le test de Papanicolaou au moins une fois, et 85,5\% des femmes qui ne l'avaient jamais passé étaient prêtes à s'y soumettre à condition qu'il soit sans douleur et simple. Plus de la moitié des femmes interrogées souhaitait que le test soit réalisé au centre de soins de santé primaires, en consultation gynécologique de dépistage. Les connaissances et les pratiques en matière de cancer du col étaient insuffisantes chez les femmes de moins de 30 ans, les jeunes mariées et celles ayant un faible niveau d'études.

${ }^{7}$ Department of Family Medicine; ${ }^{2}$ Department of Public Health Medicine \& Health Promotion, Primary Health Care, Hamad Medical Corporation, Qatar. (Correspondence to F.M. Al-Meer:dr.fathiya@yahoo.com). ${ }^{3}$ Hamad Medical Corporation, Doha, Qatar.

Received: 30/04/09; accepted: 16/09/09 


\section{Introduction}

Internationally, cervical cancer has been regarded as the third most common form of cancer among women after breast and colorectal cancer [1]. However, it is considered one of the most preventable cancers [2]. Population-based cervical smear screening programmes for cervical cancer have shown the effectiveness of screening in reducing mortality [3-6]. The risk factors for cervical cancer include early age at first intercourse and multiple sexual partners. A male consort who in turn has had intercourse with multiple women and smoking also confer significant risk. Research evidence has suggested that infection with human papilloma virus (HPV) significantly increases the relative risk for developing cervical cancer. HIV infection may also increase a woman's risk for cervical neoplasia [7].

Papanicolaou cytological testing (Pap smear) permits cervical lesions to be detected before they become cancerous, effectively reducing the incidence of cervical cancer by $75 \%-90 \%$ [8]. It is claimed that the majority of cervical cancer (theoretically up 90\%) could be prevented if all women were offered and complied with high quality cytological screening programs [9]. Several institutes have recommended Pap smear screening for every sexually active woman, for instance, the American preventive services task force recommended Pap smears at least every 3 years for women who have been sexually active and have a cervix [9]. Although cervical cancer is the most common cancer of women in developing countries, it is estimated that only about $5 \%$ of women have been screened for the disease with Pap smears, compared to $40 \%-50 \%$ in developed countries [10]. The poor uptake of the cervical cancer screening may be attributed to the lack of communication between healthcare workers and patients regarding availability and benefits of the screening. In many developing countries, women's knowledge of cervical cancer is very limited. It has been demonstrated that the vast majority of women in some African countries had not heard of cervical cancer and even more knew nothing about cervical screening $[11,12]$. In Qatar, where cervical cancer is responsible for $50 \%$ of diagnosed gynaecological cancers [13], there is no previous study that has assessed the knowledge, attitude and practices regarding cervical cancer among females of reproductive age. Therefore we aimed to collect information concerning knowledge, attitude and practices towards cervical cancer and the Pap smear test.

\section{Methods}

In this cross-sectional study we recruited 500 females attending 5 primary health care centres which had been randomly selected by simple random sampling from a list of 21 health centres in $\mathrm{Qa}$ tar. The participants were selected by systematic random sampling by choosing every 10th adult female visiting the health centre for any reason, medical or non-medical during November and December 2008.

Data collection was done during November and December 2008 using a validated questionnaire that was adopted from previous studies $[12,14,15]$. The questionnaire was translated into Arabic and then translated back to English by a different person to assess validity. It was pilot-tested in a sample of 40 women who were not part of the study sample to ensure cultural acceptance and level of validity and degree of repeatability $(\kappa=0.85)$. The questionnaire consisted of 20 items that addressed personal data and question about knowledge, attitudes and practices with regard to cervical cancer screening. Personal data included age, education level, marital status, parity, number of miscarriages, occupation status, husband's education and duration of marriage. Knowledge and beliefs about cervical cancer and screening were tested with the following items: whether the respondent had ever heard of cervical cancer, had ever heard that Pap smear is used to detect cervical cancer, knew the risk factors that may lead to cervical cancer, knew the early detection of cervical cancer leads to better treatment and whether is it possible to cure this cancer. The respondent's attitude was ascertained with the following items: whether they had ever had a Papanicolaou smear, if they were told that the smear test was a simple, painless procedure and could lead to early detection and treatment of cervical cancer, would they like to have one, where they would prefer to have the smear test. The questionnaire was administrated through face-to-face interviews with females assigned to the study and with the support of a receptionist, a patient care assistant and a physician for explanation, especially for illiterate women and for any unclear questions.

Data were entered into SPSS, version 14. The knowledge score was calculated by adding all positive responses of 7 items, each item was assigned 1 for a positive response and 0 for no response and all 7 items were included in the score. The mean score for knowledge was calculated comparing demographic characteristic by 1-way analysis of variance post hoc (Bonferroni) test for multiple comparisons. $P$-value $<0.05$ was considered statistically significant.

\section{Results}

The study included 500 women; the mean age was 42.2 (standard deviation 7.2 ) years. Over $35 \%$ had parity $\geq 4$ times. Tablel shows demographic data for the participants. Over $80 \%$ had heard about cervical cancer and about three quarters had heard about the Pap smear (Table 2). The main source of information about the Pap smear was relatives and friends (21.6\%). Sexually 


\begin{tabular}{|c|c|c|}
\hline Characteristic & No. & $\%$ \\
\hline \multicolumn{3}{|l|}{ Age (years) } \\
\hline $20-29$ & 158 & 31.6 \\
\hline $30-39$ & 176 & 35.2 \\
\hline $40 \geq$ & 166 & 33.2 \\
\hline \multicolumn{3}{|l|}{ Education level } \\
\hline Illiterate & 16 & 3.2 \\
\hline Primary & 20 & 4.0 \\
\hline Preparatory & 44 & 8.8 \\
\hline Secondary & 131 & 26.6 \\
\hline University or equivalent & 289 & 57.8 \\
\hline \multicolumn{3}{|l|}{ Marital status } \\
\hline Married & 441 & 88.2 \\
\hline Never married & 31 & 6.2 \\
\hline Divorced & 16 & 3.2 \\
\hline Widowed & 12 & 2.4 \\
\hline \multicolumn{3}{|l|}{ Parity } \\
\hline Nullipara & 100 & 20.0 \\
\hline 1 & 62 & 12.4 \\
\hline 2 & 64 & 12.8 \\
\hline 3 & 84 & 16.8 \\
\hline$\geq 4$ & 190 & 38.0 \\
\hline \multicolumn{3}{|c|}{$\begin{array}{l}\text { No. miscarriages or voluntary } \\
\text { terminations of pregnancy }\end{array}$} \\
\hline 0 & 339 & 67.8 \\
\hline 1 & 87 & 17.4 \\
\hline 2 & 29 & 5.8 \\
\hline$\geq 3$ & 45 & 9.0 \\
\hline \multicolumn{3}{|l|}{ Employment status } \\
\hline Employed & 246 & 49.2 \\
\hline unemployed & 254 & 50.8 \\
\hline \multicolumn{3}{|l|}{ Husband's education } \\
\hline Illiterate & 35 & 7.0 \\
\hline Primary & 26 & 5.2 \\
\hline Preparatory & 57 & 11.4 \\
\hline Secondary & 118 & 23.6 \\
\hline University or equivalent & 264 & 52.8 \\
\hline \multicolumn{3}{|l|}{ Duration of marriage (years) } \\
\hline Not married & 23 & 4.6 \\
\hline $1-5$ & 134 & 26.8 \\
\hline $6-10$ & 103 & 20.6 \\
\hline $11-20$ & 127 & 25.4 \\
\hline$>20$ & 113 & 22.6 \\
\hline
\end{tabular}

transmitted disease was ranked first as detect cancer before the appearance a risk factor for cervical cancer (24.8\%). of symptoms and around two-thirds About two-thirds of the participants $(64.8 \%)$ believed that the Pap smear (62.4\%) believed that the Pap smear can could improve treatment outcome.
The mean knowledge score was significantly higher among women aged 30-49 years, those who had a university degree, were employed, had been married for more than 15 years, had parity $\geq 4$, or had had $\geq 3$ miscarriages $(P<0.05)$ (Table 3$)$. Of the 500 women who participated in this study, 197 (39.4\%) had had a Pap smear at least once in their life. The majority of women $(85.5 \%)$ said they would have a Pap smear if they were told that the procedure was painless and simple. More than half would prefer the test to be done in the well-women clinic at the primary health care centre (Table 4).

\section{Discussion}

This survey provides baseline information for planning a cervical cancer prevention programme in Qatar. It is well known individuals' knowledge and beliefs about the cause and significance of a particular illness are interconnected with their healthcare-seekingbehaviours [14]. The results showed a deficiency in knowledge about cervical cancer as well as low Pap smear uptake, which was surprisingly common among the educated women. Such findings have been reported by a number of previous studies in Arab communities. For example in the United Arab Emirates, a study of knowledge, attitude and practice among female school teachers in Sharjah has shown that, although the teachers had good knowledge about the Pap smear test, they were not commonly practising it [15]. In Jordan, the knowledge of cervical cancer and the Pap smear test was inadequate in less-educated and older patients [16]. Of the women who had previously had the test, $95.4 \%$ had opportunistic testing. Around 95\% of the sample had never had the test. In Kuwait, a 2008 study showed that about $52 \%$ of women hadadequate knowledge about cervical cancer screening [17].

Apart from inadequate knowledge, it is well known that the most frequently 


\begin{tabular}{|c|c|c|}
\hline Knowledge/belief item & No. & $\%$ \\
\hline \multicolumn{3}{|l|}{ Have you ever heard about the Pap smear? } \\
\hline Yes & 382 & 76.4 \\
\hline No & 118 & 23.6 \\
\hline \multicolumn{3}{|c|}{ Where did you hear about the Pap smear for the first time? } \\
\hline Relatives, friends & 108 & 21.6 \\
\hline Gynaecologist & 95 & 19.0 \\
\hline Mass media (newspaper, internet, television) & 80 & 16.0 \\
\hline Family physician & 72 & 14.4 \\
\hline Nurse & 20 & 4.0 \\
\hline Other & 125 & 25.0 \\
\hline \multicolumn{3}{|l|}{ Know about the cervical cancer } \\
\hline Yes & 426 & 85.2 \\
\hline No & 74 & 14.8 \\
\hline \multicolumn{3}{|c|}{ Knowledge of the risk factors which can lead to cervical cancer } \\
\hline Sexually transmitted disease & 124 & 24.8 \\
\hline Smoking & 54 & 10.8 \\
\hline Multiple partners & 34 & 6.8 \\
\hline Early age of marriage, $<18$ years & 31 & 6.2 \\
\hline Marriage to man with other women & 24 & 4.8 \\
\hline Diet & 13 & 2.6 \\
\hline \multicolumn{2}{|c|}{ Is it possible to detect cervical cancer with the Pap smear before } & 44.0 \\
\hline Yes & 312 & 62.4 \\
\hline No & 188 & 37.6 \\
\hline \multicolumn{3}{|c|}{ Is early detection of cervical cancer good for treatment outcome? } \\
\hline Yes & 324 & 64.8 \\
\hline No & 176 & 35.2 \\
\hline \multicolumn{3}{|l|}{ Is it to possible to cure cervical cancer? } \\
\hline Yes & 412 & 412 \\
\hline No & 88 & 88 \\
\hline
\end{tabular}

reported reasons for not having a recent Pap smear were belief that it might be painful, followed by embarrassment, not being referred by a health professional, and fear of having positive results $[15,16]$. In the present study, the poor level of knowledge was related to illiteracy and unemployment, which also indicates educational status the majority of employed women in Qatar are educated. This relation between education and knowledge has been reported in previous studies in Arab and Hispanic women [17-20]. The study also shows that the level of knowledge was higher the longer the marriage and in those with greater parity. In agreement with other studies from Arab countries [17], Latin and Asian communities [20-22], our study showed that women $>50$ years had poor knowledge about cervical cancer and screening; in fact most of the illiterate women in Qatar are in this age group. More interestingly, we found that even young women, 20-29 years, had poor knowledge even though this group is educated. One of the significant finding in this study was that the majority women got their knowledge about cervical cancer screening from their social network (relatives and friends) rather than physicians or the media.
This can be attributed to the absence of a well organized cervical cancer screening programme, which would include mass media awareness and practice guidelines encouraging family physicians to advise their patients to have a smear test. The well women clinic, however, provides the Pap smear test in most of the primary health centres in Qatar. Another possible factor is the fear and embarrassment that may be associated with cervical cancer screening; this does not encourage women and health care workers to discuss the issue. We found that most of our participants preferred to have the test at the well 


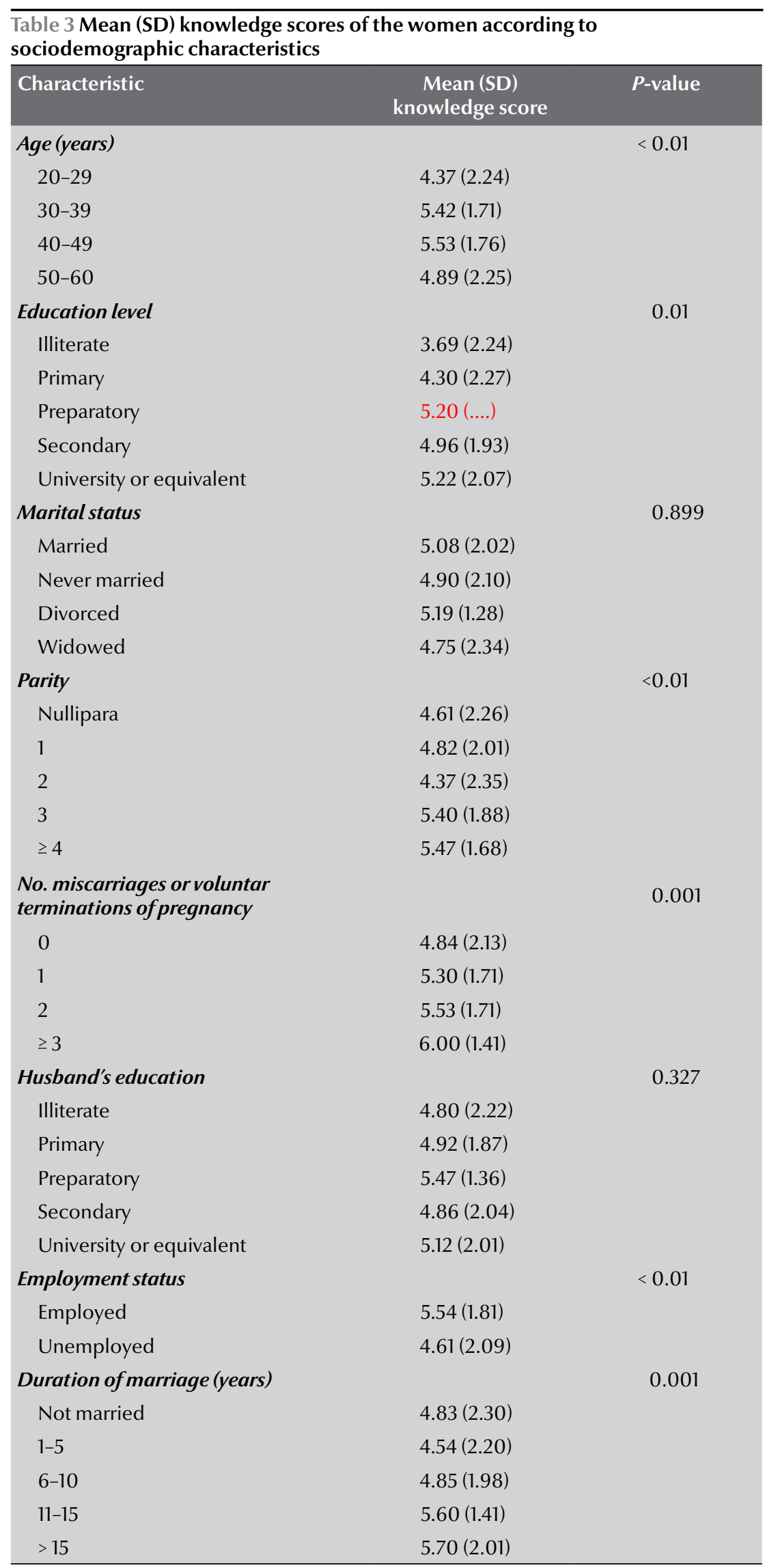

$S D=$ standard deviation. women clinician the primary health care centre rather than a gynaecology clinic in a hospital. This can give more encouragement for primary health care providers to market for well women clinics as the ideal setting for any national cervical cancer screening programme. A possible explanation for this positive attitude is the easy access to the primary care clinics.

It has been estimated that only about $5 \%-10 \%$ of women in developing countries [11,21-24] have been screened for cervical cancer with a Pap smear compared to $40 \%-50 \%$ in developed countries [23]. In our study almost $40 \%$ of the women had had at least 1 Pap smear, approaching the level of developed countries. This is even greater than the $23.8 \%$ in a Kuwaiti study [17]. Most women in this study, however, stated that they would have the test if they have been told that it was painless. These beliefs about cervical cancer and the smear test have been documented as determinants of an individual's participation in cancer screening $[18,25]$.

Other factors that can increase Pap smear uptake such as the presence of sexually transmitted diseases and a positive family history of cervical cancer were not investigated as many women in our culture consider this information confidential and sensitive, although such information is valuable and is known to affect screening utilization [26].

In conclusion, our results show that there was inadequate knowledge and practice among certain women groups, especially those under 30 years old, recently married, and those with low education level. However, women in Qatar have a positive attitude towards cervical screening services although they need to have reassurances that can reduce the barriers to having a test.

A well organized cervical cancer screening programme providing the Pap 


\begin{tabular}{lcc}
\hline Table 4 Attitude and practice of women toward cervical cancer screening & No. \\
\hline Attitude/practice item & 197 & 39.4 \\
Have ever had a Pap smear done? & 303 & 60.6 \\
$\quad$ Yes & & \\
No & 429 & 85.8 \\
Ifyou were told that a Pap smear is simple,painless and good for early detection of & 71 \\
cervical cancer, would like to have one? & & 14.2 \\
Yes & 277 \\
No & 108 \\
Where would you prefer to have this test done? & 39 \\
Well women clinic in the primary health care centre & 55.4 \\
Gynaecology clinic in hospital & 76 \\
Private clinic & 21.6 \\
No preference & 7.8 \\
\hline
\end{tabular}

smear test through primary health care services is recommended: this should include raising awareness of women regarding risk factors, and overcoming barriers to having the test such as fear and embarrassment.

\section{Acknowledgements}

The authors thank the Medical Research Centre for giving ethical approval to conduct the study and Dr Riyvis Singh for analysis of the study data. Thanks also go to the volunteer patient care assistant whose collaboration made this work possible. The authors' sincere appreciation goes to all the women who completed the questionnaire.

\section{References}

1. Parkin DM, Pisani P, Ferlay J. Estimates of the worldwide incidence of 25 major cancers in 1990. International Journal of Cancer, 1999, 80(6):827-841.

2. Pontin J et al. Strategies for global control of cervical cancer. International Journal of Cancer, 1995, 60(1):1-26.

3. Bergstrom R, Sparen P, Adami HO. Trends in cancer of the cervix uteri in Sweden following cytological screening. British Journal of Cancer, 1999, 81(1):159-166.

4. Mahlck CG, Jonsson H, Lenner P. Pap smear screening and changes in cervical cancer mortality in Sweden. International Journal of Gynaecology and Obstetrics, 1994, 44:267-272.

5. Morris $\mathrm{M}$ et al. cervical intraepithelial neoplasia and cervical cancer. Obstetric \& Gynecology Clinics of North America, 1996, 23:347-410.

6. Elovainio L, Nieminen P, Miller AB. Impact of cancer screening on women's health. International Journal of Gynaecology and Obstetrics, 1997, 58(1):137-147.

7. Arevian $\mathrm{M}$ et al .A survey of knowledge, attitude, and practice of cervical screening among Lebanese/American women. Nursing Outlook, 1997, 45(1):16-22.

8. The national breast and cervical cancer early detection program. Atlanta, Centers for Disease Control and Prevention, US Department of Health and Human Services, 1995.

9. Healthy people 2000: national health promotion and disease prevention objectives. Washington DC, Department of Health and Human Services, United States Government Printing Office, 1990 .

10. Musmar SG. Pattern and factors affecting Pap smear test in Nablus, a retrospective study. Middle East Journal of Family Medicine, 2004, 4(4) (http://mejfm.com/journal/MEJFM\%20 Feb\%202004/Pap\%20smear1.htm, accessed 28 September 2011).
11. Ayayi IO, Adewole IF. Knowledge and attitude of general outpatient attendants in Nigeria to cervical cancer. Central African Journal ofMedicine, 1998, 44(2):41-43.

12. Kidanto HL, Kilewo CD, Moshiro C. Cancer of the cervix knowledge and attitudes of female patients admitted at Muhimbili National Hospital, Dar es Salaam. East African Medical Journal, 2002, 79(9):745-467.

13. Al Sakka M et al. Gynecological malignancies in Qatar. Qatar Medical Journal, 1999, 8(2):73.

14. Kleinman A, Seeman D. Personal experience of illness. In: Scrimshaw S. ed. Handbook of social studies in health and medicine. Thousand Oaks, California, Sage, 2000:230-242.

15. Bakheit NM, Buharooon AL. The knowledge, attitude, and practice of Pap smear among local school teachers in the Sharjah district. Middle East Journal of Family Medicine, 2004, 4(4). (http://mejfm.com/journal/MEJFM\%20Feb\%202004/Pap1. htm, accessed 28 September 2011).

16. Amarin ZO, Badria LF, Obeidat BR. Attitudes and beliefs about cervical smear testing in ever-married Jordanian women. Eastern Mediterranean Health Journal, 2008, 14(2):389-397.

17. Al Sairafi M, Mohamed FA. Knowledge, attitudes, and practice related to cervical cancer screening among Kuwaiti women. Medical Principles and Practice, 2009, 18(1):35-42.

18. Bener A, Denic S, Alwash R. Screening for cervical cancer among Arab women. International Journal of Gynaecology and Obstetrics, 2001, 74(3):305-307.

19. Morgan C, Park E, Cortes DE. Beliefs, knowledge, and behavior about cancer among urban Hispanic women. Journal of the National Cancer Institute Monographs, 1995, (18):57-63.

20. Ramirez AG et al. Hispanic women's breast and cervical cancer knowledge, attitudes, and screening behaviors. American Journal of Health Promotion, 2000, 14(5):292-300. 
21. Roy B, Tang TS. Cervical cancer screening in Kolkata, India: beliefs and predictors of cervical cancer screening among women attending a women's health clinic in Kolkata, India. Journal of Cancer Education, 2008, 23(4):253-259.

22. Ho $\mathrm{V}$ et al. Predictors of breast and cervical screening in Vietnamese women in Harris County, Houston, Texas. Journal of Cancer Education, 2008, 23(4):253-259.

23. Lauver D. Addressing infrequent cancer screening among women. Nursing Outlook, 1992, 40(5):207-212.

24. McFarland DM. Cervical cancer and Pap smear screening in Botswana: knowledge and perceptions. International Nursing Review, 2003, 50(3):167-175.
25. Maaita M, Barakat M. Jordanian women's attitudes towards cervical screening and cervical cancer. Journal of obstetrics and gynaecology, 2002, 22(4):421-422.

26. Dhamija S, Sehgal A, Sehgal K. Factors associated with awareness and knowledge of cervical cancer in a community: implication for health education programmes in developing countries. Journal of the Royal Society of Health, 1993, 113(4):184-186

\section{Cancer survival in Africa, Asia, the Caribbean and Central America}

Population-based cancer survival rates offer an important benchmark for measuring a health care system s overall effectiveness in the fight against cancer. While this type of information on high-resource countries is readily available, Cancer survival in Africa, Asia, the Caribbean and Central America presents in-depth cancer survival data from 27 population-based cancer registries in 14 low- and middle-resource countries.

The striking inequalities in cancer survival between countries and within countries described in this volume are largely related to the differences in general awareness, availability of early detection practices, trained human resources, diagnosis and treatment and the development and accessibility to cancer services, as well as, to a lesser extent, to issues of data quality and reliability.

The differences in cancer survival reported in populations observed between and within countries studied in this volume provide valuable insights for future planning and investment by governments in primary prevention activities, early detection initiatives and tertiary care to achieve meaningful cancer control.

The calendar period of registration of incident cases for the present study ranges between 1990 and 2001. Data on 564606 cases of 1-56 cancer sites from different registries are reported. Data from 11 registries were used for eliciting survival trends and 17 registries for reporting survival by clinical extent of disease. Besides chapters on every registry and general chapters on methodology, database and overview, the availability of online comparative statistics on cancer survival data by participating registries or cancer site in the form of tables or graphs is an added feature.

Further information about this and other WHO publications is available at: http:/ /www.who.int/publications/en/ 